The Malaysian Journal of Social Administration, 10: 1-28.

\title{
PROTECTING CHILDREN FROM TRAFFICKING: RESPONSES OF THE GOVERNMENTAL AND NON- GOVERNMENTAL ORGANISATIONS IN BANGLADESH
}

\author{
M. Rezaul Islam, PhD \\ Senior Lecturer, Department of Social Administration \& Justice, Faculty of Arts and Social \\ Sciences, University of Malaya, 50603 Kuala Lumpur, MALAYSIA \\ rezaul@um.edu.my \\ Delwar Hossain, PhD \\ Professor, Department of International Relations, University of Dhaka, Dhaka-1000, \\ BANGLADESH \\ h.delwar@gmail.com
}

\begin{abstract}
This paper explores the features of child trafficking in Bangladesh and then addresses the responses of the governmental and non-governmental organizations (GOs and NGOs) to the problem. It aims at analysing the sources and causes of child trafficking. The paper also aims to discuss the current initiatives of the GOs and NGOs with its limitations, and finally provides some way out alternatives. The paper argues that the GO-NGO responses are inadequate in the light of the Convention on the Rights of the Child (CRC) in Bangladesh. The paper contributes a dynamic and multidimensional understanding of how the GOs and NGOs combating child trafficking issue in Bangladesh.
\end{abstract}

Keywords: Child rights, child welfare, Convention on the Rights of the Child (CRC), child trafficking, child labour, child protection, Bangladesh.

\section{INTRODUCTION}

Children are an integral part of a nation's development. They are the greatest asset of any country. In reality, children confront a world where their rights and needs are deprived. There is no way to enumerate thoroughly the various ways in which children around the world are being economically and physically mistreated (United 
Nations, 2014). However, the numbers are high, and the suffering is widespread. Bangladesh is no exception to this. Children in Bangladesh struggle to survive. They have been victims of injustice and poverty, exploited as child labourers or prostitutes, drafted as young teenagers into organized criminal forces, forced into a lonely life as domestic workers, deprived of education to work on the family farm, or denied adequate nutrition and health care (United Nations, 2014).

While children suffer from several kinds of oppression, injustice and deprivation in the society, trafficking is the worst of all. In fact, child trafficking is one of the worst forms of child labour in the world. As reported by the International Labour Organization (ILO), in spite of many efforts from different actors and numerous perspectives, both internal and cross-border trafficking of children for labour and sexual exploitation remains a significant problem of the world. This can be partly attributed to the lack of deterring punishments for the perpetrators (Coomaraswamy and Satkunanathan, 2006). In many countries, the legal instruments and their enforcement mechanisms are inadequate to punish and bring the traffickers to justice. New laws have been introduced in some countries, yet they are not sufficiently stringent and comprehensive to deal with the problem. For instance, in many countries, the anti-trafficking laws cover only trafficking for sexual exploitation but do not include trafficking for labour exploitation. On the other hand, where there are existing laws, they often are not enforced because of a lack of understanding and inappropriate attitudes toward the whole problem (Coomaraswamy and Satkunanathan, 2006).

Against this backdrop, the focus of the paper is protection, which is critically important to design appropriate responses to the menace of child trafficking. Undoubtedly, the future of every nation in the world lies with the children. Bangladesh is no exception. In fact, for a country like Bangladesh children are the future human resources, a critical force for national development of the country. There are three ways to respond to child trafficking - prevention, protection and prosecution. Protection as a response cut across other ways - prevention and prosecution. 


\section{BACKGROUND AND CONCEPTUAL FRAMEWORK OF CHILD TRAFFICKING}

Historically, there have been inconsistencies and disagreements regarding the definition of human trafficking among politicians, practitioners, and scholars (Laczko and Gramegna, 2003; Richard, 1999). While trafficking as an international legal concept has been in the vogue since the early twentieth century, the phenomenon of child trafficking received global attention only in the late 1940s. The 1949 Convention on the Suppression of the Traffic in Persons and of the Exploitation of the Prostitution of Others, the first trafficking convention to use gender-neutral language, also makes no mention of children. The Supplementary Convention on the Abolition of Slavery, the Slave Trade and Institutions and Practices Similar to Slavery 1956 is the first convention to deal with the exploitation of children related to slavery and similar practices. The International Organization for Migration (IOM) report does not give a clear definition of child trafficking. The report does not address four main issues of child trafficking. First, the actual 'outcome' of the trafficking event (e.g. the situation a person is placed into). Second, the various incidences of torture, rape, intimidation and threats used to ensure that the victims comply with their new situation. Third, the 'slavery-like' conditions they must endure over time. Fourth, the issue of evolution or temporal nature of the event.

The problem of defining child trafficking is partly linked with the age of a child. Who is a child? According to the Convention on the Rights of the Child (CRC), the ILO Convention on Minimum Age for Admission to Employment and the ILO Convention No. 182: Worst Forms of Child Labour Convention, 1999, a child is defined as a person under the age of 18 . There is a lack of uniformity about what constitutes a child for trafficking and not all countries adopt the 18-year threshold recommended by the CRC. Different states maintain different age limits to categorize a person child or not. There is a tendency for the trafficking debate and related understanding of the phenomenon, to gravitate into a criminal approach, on the one hand, and a human rights or protection approach on the other hand. This creates a false impression of opposing perspectives when, in reality, both dimensions 
are inherently linked and are essential to prevent and combat trafficking (UNICEF, 2003). There is another dimension to understand child trafficking, which is linked with its supply and demand sides. Based on the movement of trafficked children, there are three categories of states - 'destination' or 'user'; 'origin' or 'source'; and 'transit' countries. There is a tendency to blame supply side of child trafficking as often demonstrated by the actions of many Northern countries particularly the USA. As one analyst poses question, 'If the sex industry, a slave trade, etc. continue their billion-dollar business then how will the entire chain stop? Is it only in the hands of the governments of the so-called source countries to control such trade?'

Lack of conceptual clarity remained a major problem in the understanding of child trafficking. It points to the need for greater awareness and training at the regional level and timely intervention at the drafting stage by national and international experts who have a familiarity with the subject (ILO, 2005). There is an agreement on the fact that trafficking of children is a form of human trafficking. It may be mentioned that child trafficking cannot be defined without reference to a host of international legislation. The United Nations Protocol to Prevent, Suppress and Punish Trafficking in Persons, especially Women and Children, supplementing the United Nations Convention against Transnational Organized Crime (2000) are the most influential document. The Protocol had been ratified by 135 countries. According to the Protocol:

Trafficking in persons shall mean the recruitment, transportation, transfer, harbouring or receipt of persons, by means of the threat or use by force or other forms of coercion, of abduction, of fraud, of deception, of the abuse of power or of a position of vulnerability or of the giving and receiving of payments or benefits to achieve the consent of a person having control over another person, for the purpose of exploitation. Exploitation shall include, at a minimum, the exploitation of the prostitution of others or other forms of sexual exploitation, forced labour or services, slavery or practices similar to slavery, servitude or the removal of organs 
According to United Nations (2000):

Child trafficking is defined as the recruitment and transfer of individuals for the purpose of exploitation for sexual or other forms of labour by means of threat or the use of threat or coercion, kidnapping, fraud, or deception that include the abuse of power and control of others. For children, trafficking occurs in any situation in which they are being recruited, transferred, or received for the purpose of exploitation

(United Nation, 2000)

According to the State Department of the USA:

All acts involved in the recruitment, transport, harbouring, and sale of persons within and across international borders through deception or fraud, coercion or force, or debt bondage, for the purpose of placing a person in a situation of forced labour or services, such as forced prostitution or sexual services, domestic servitude or other forms of slaverylike practices

(USA State Department, 2005a)

Based on the above definitions, we can conclude that child trafficking encompasses all forms of action undertaken by perpetrators of trafficking. Child trafficking have one or more elements of recruiting, transporting between regions and countries, transferring, sending, receiving and temporary placement or placement at their destination of children by using threats, verbal and physical abuse, abduction, fraud, deception, misuse of vulnerability (e.g. if someone has no alternative, is isolated, is addicted to drugs, trapped in debt), giving or receiving payments or profits in cases in which a child is used for prostitution and sexual exploitation, legal or illegal migrant workers, adoptions, fishing platform work, mail order brides, domestic helpers, begging, pornography, drug dealing, selling of body organs as well as other forms of exploitation. 
The basic elements of trafficking are movement of a person from one location to another for the purpose of slavery, slavery like practices or exploitation (ILO, 2005: 9). Child trafficking is a crime under international law and under the national legislation of many countries. Commercial sexual exploitation of children can take many forms and include forcing a child into prostitution or other forms of sexual activity or child pornography. Child exploitation can also include forced labour or services, slavery or practices similar to slavery, servitude, the removal of organs, illicit international adoption, trafficking for early marriage, recruitment as child soldiers, for use in begging or as athletes (such as child camel jockeys or football players), or for recruitment for cults. According to international legislation, in the case of children the use of force or other forms of coercion, abduction, fraud, deception, the abuse of power or position of vulnerability does not need to be present in order for a crime to be considered trafficking.

\section{METHODOLOGY}

The main objective of this paper was to explore the responses of the governmental and non-governmental (GOs and NGOs) of Bangladesh to the child trafficking issue. To attain this objective, the paper addresses these questions:

i) What do we mean by child trafficking?

ii) What are the global and local (Bangladesh) features (i.e., nature and causes, and consequences) of child trafficking?

iii) How do the government and non-government of Bangladesh responses to combat the problem of child trafficking in Bangladesh?

The paper is based on content analysis used existing available literature. We followed the similar type of paper written by Joffres et al., (2008). Content analysis is the systematic description of behaviour asking who, what, where, and how questions within formulated systematic rules to limit the effects of analyst bias. The search for relevant literature was completed in two stages. First, we examined peer reviewed articles that we found in electronic databases using keyword searches including child trafficking, child trafficking in global context, and child trafficking in Bangladesh, and GO-NGO responses for combating child trafficking. We used a 
number of search toolbars such as Academic Search Premier, Academic Common, Aseline, Informit, Ingenaconnect, ScienceDirect, Scopus, Social Science Citation Index and SSRN, and PsycARTICLES. In the second stage, we used the "snowball" method by searching for journal articles and reports, as well as articles presented in peer reviewed conferences that are cited in some of the articles that we had read. Altogether, as at 21 March 2013, we read 136 articles and deleted 92. The 92 articles were discarded because they were opinion papers, conceptual articles, non-empirical descriptions of programme implementations, and literature reviews. Finally, we considered 22 articles and eight reports which we found more relevant for this paper. We also reviewed relevant published and unpublished national and international reports and documents including the reports published by ILO, UNICEF, and United Nations, and Research reports. Some of the significant articles and reports are listed in the reference section. We did not summarize findings of previous research; rather we critically analysed those.

The basic unit of analysis was the individual empirical articles and reports. During the course of our analysis, we also allowed for new categories (if any) to emerge inductively. We employed the constant-comparative or grounded approach espoused by Lincoln \& Guba (1985). This approach is similar to the iterative pattern coding method (Miles \& Huberman, 1994). Specifically, the various categories of research methods, data collection methods, as well as research topics were not predetermined prior to our analysis but emerged inductively and were continually refined through our interaction with the data.

\section{CHILD TRAFFICKING: NATURE AND CAUSES}

\section{Global}

Trafficking in general and child trafficking in particular has received increased attention over the last decade (ILO-IPEC, 2001; Lazaridis, 2001; Bastia, 2005). However, the global statistical data available is, at best, illustrative because of the illegal nature of trafficking. A number of in-depth studies have been produced in the 
last decade though these have been uneven in their geographical coverage as well as in the issues they have addressed (Basita, 2005). For example, there are many studies covering trafficking for sexual exploitation, with fewer dealing with trafficking for labour exploitation (e.g. Altink, 1995; Bertone, 2000; ILO-IPEC, 2001; IOM, 1995, 2005; Lazaridis, 2001). This imbalance is brought to light in the research that define trafficking and traffickers only in relation to the sex industry (e.g. Raymond and Hughes, 2001). Geographically speaking, most studies focus on Asia and Europe (e.g. Blanchet, 2002; Foundation of Women's Forum, 1998; Ministry for Foreign Affairs, 2001). Africa has also received some attention; especially more recently (see Human Rights Watch, 2003; Save the Children Canada, 2003; UNICEF, 2002).

The most neglected region is South America. Here, trafficking has yet to start gaining some attention. Although there is a general perception that trafficking is not as significant in South America as it is in the other regions until more research on this issue starts emerging, this cannot be confirmed with certainty. Moreover, available information indicates that trafficking is, as in some African countries, linked with traditional forms of patronage and, therefore, it is often not perceived as trafficking (Basita, 2005).

Reports on the State of Child in the World as published from various sources show that around fifty percent of all trafficking victims are women and children. Every year, 1.2 million children are trafficked for child labour. Another one million children are annually trafficked into the global sex trade. Although no precise figures exist, the ILO (2005) estimated that 980,000 to $1,250,000$ children, both boys and girls, are in a forced labour situation because of trafficking. According to the ILO (2005), 550,000 children were trafficked from the Latin America and Caribbean, 250,000 from Asia Pacific and 200,000 from both Africa and developed and industrialized economies (Table 1).

UNODC (2012) published the recent report based on a study on official data supplied by 132 countries from 2007-2010. According to this report, the majority of trafficked persons are women, accounting for 55 to 60 per cent of victims detected globally. Children, most of them girls, now made up 27 per cent of all human 
trafficking cases, marking an alarming increase in recent years. Girls under 18 made up two thirds of all trafficked children and now constitute 15-20 per cent of the total number of all detected victims. UNICEF estimates that 1,000 to 1,500 Guatemalan babies and children are smuggled each year for adoption by couples in North America and Europe. Asia and Eastern Europe girls, as young as 13 years old are trafficked as 'mail-order brides' to other continents. In most cases, these girls and women are powerless and isolated and at high risk of violence. The large numbers of children are being trafficked in the West and Central Africa, mainly for domestic work and for sexual exploitation and to work in shops or on farms. Children from Togo, Mali, Burkina Faso and Ghana are trafficked to Nigeria, Ivory Coast, Cameroon and Gabon. Children are trafficked in and out of both Benin and Nigeria. Some children are sent as far away as the Middle East and Europe.

Table 1: Region-wise source of child trafficking

\begin{tabular}{ll}
\hline Region (source) & Trafficked children \\
\hline Asia Pacific & 250,000 \\
Latin America and Caribbean & 550,000 \\
Africa & 200,000 \\
Transition economies & 200,000 \\
Developed and industrialized economies & $\mathrm{n} / \mathrm{a}$ \\
Total (rounded) & 1200,000 \\
\hline
\end{tabular}
Source: ILO (2005)

Causes of child trafficking have been differed widely due to the socioeconomic and political conditions of a country. It is agreed that children who had limited education and work on the streets are at the greatest risk of trafficking. Children who come from poor and problematic families are as well as at greatest risk of trafficking. In a poor and developing countries, trusted community members usually recruited the children by promising that the children would work to help the family financially. Once abroad, the children were harshly treated, forced to work long hours, physically abused, and isolated from family members. Families did not receive the promised payment. Once returned, children had a difficult time reentering due to family, educational, and economic issues (Gjermeni et al., 2008). In 
particular, children from the most disadvantaged groups are at high risk of being trafficking victims. They and their parents are frequently misled about the reality of employment awaiting them (Dottridge, 2004; Firoze, 2006; Mattar, 2003; Renton, 2001; United Nations Children's Fund, 2005, United Nations Children's Fund, 2006; US Department of State, 2005).

Poverty is a major reason for human trafficking. People take desperate measures to improve their own or their family circumstances. Poor women and children are forced to move from poorer to more developed and wealthier countries to participate in the sex trade industry. They are also moved within their own countries to typically serve the sexual needs of wealthier individuals, frequently from abroad (Bump and Duncan, 2003; Dottridge, 2004, Lederer, 2001, Mattar, 2003; Ryan and Hall, 2001; United Nations Children's Fund, 2005 and United Nations Children's Fund, 2006). Heissler (2013) recently discovers that the relationship between movement and work is central for labour migration, yet concerning children's migration for work, it has mostly been associated with exploitation and trafficking. The findings presented challenge the assumption that child labour migration is necessarily a form of trafficking and that poor people, especially children, are easily taken advantage. Other important factors contributing to placing children at risk of trafficking include cultural traditions that support child labour, family breakdown due to the death of parents or other problems, historical migration patterns, ignorance of the reality of trafficking, socio-cultural codes that devalue education of girls, and political instability and corruption (Africa Research Bulletin, 2004; Firoze, 2006; Human Rights Watch, 2003, Lederer, 2001, Sanghera, 1999; United Nations, 2004; UNICEF, 2006).

\section{Bangladesh}

Child trafficking for labour and sexual exploitation is prevalent in Bangladesh. In fact, Bangladesh is one of the worst countries for child trafficking. Surveys by different organizations reveal that the scenarios of children trafficking for the last five years are alarming. It shows that about 87,000 rescued children were confined to be trafficked within and outside Bangladesh. No one knows how many children had 
been trafficked. According to Bangladesh National Women Lawyers Association, about 25,000 women and children are trafficked in Bangladesh (Alamgir, 2004). Bangladesh is a country of origin and transit for trafficked persons. Internal and external migration is taking place at a rapid rate with urban growth of 5.6 per cent. The urban population is estimated to reach 67 million by 2025. This trend has also increased the vulnerability of children whose families move to urban areas only to face unemployment and, therefore, may feel pressure to subject their children to exploitative situations. It is reported that some child rural-urban migrants are separated from their parents while others make the move to urban areas on their own to find a better life for themselves. Without a supportive and protective family structure, these children are extremely vulnerable to trafficking.

There are some pertinent questions, such as who are the victims, what are the common means of trafficking, and where do they go in understanding protection aspects of child trafficking in Bangladesh. Primarily, poor and illiterate groups of people in the rural areas, low income people, slum dwellers in the city or town, street children, refugees in the border regions, children in the over populated regions, and children in the coastal areas and char lands are the victims of trafficking. The most common means for trafficking include abduction, false promises of marriage, allurement and promises of jobs abroad, migration, and frustration. They usually do begging, bonded labour, sex works, child domestic labour, drug couriering, employment in risky works, flesh trade, pornography, camel jockeying, and child soldiering and exploitative or slavery-like practices in the informal industrial sector.

The children are said to be trafficked from Dhaka, consist mainly of street children and children migrating to Dhaka from rural areas such as Chittagong and Jessore. As in other countries the end products of trafficking, include sexual exploitation, domestic labour and bonded labour. Children are also trafficked from Bangladesh to the Middle East to work as camel jockeys (Government of Bangladesh, 2007). The United States Department of State (2012) states that Bangladeshi children are trafficked internally for commercial sexual exploitation, domestic servitude, forced and bonded labour, and forced begging. In some 
instances, children are sold into bondage by their parents, while others are induced into labour or commercial sexual exploitation through fraud and physical coercion. Girls and boys as young as eight years old are subjected to forced prostitution within the country, living in slave-like circumstances, in secluded environments. Trafficking within the country often occurs from poorer, more rural regions to cities. Internationally, women and children from Bangladesh are trafficked to India and Pakistan for commercial sexual exploitation or forced labour. Some Rohingya refugees from Burma have been subjected to human trafficking. Many brothel owners and pimps coerce Bangladeshi girls to take steroids to make them attractive to clients, with devastating side effects. The drug is reported to be used by 90 percent of girls and women between the ages of 15 and 35 in Bangladeshi brothels.

Globalisation has contributed to the growth of trafficking and due to the fact humans can be resold it is comparatively low risk and with the high rewards it is a profitable activity for traffickers. The push factors include poverty, power and violence, weak governance, armed conflict or lack of effective protection against discrimination and exploitation. Analyses of cases highlight the 'push factors' - on the so-called 'supply side' - and tend to neglect the market dimension of the problem. However, 'pull factors' on the demand side are of equal salience for effective counteractive measures against trafficking in women and children. Five distinct areas of the 'pull factors' which instigate trafficking in women and children that deserve particular attention are sexual exploitation, other forms of economic exploitation, traditional practices, adoption and post-conflict scenarios (Rafferty 2007; Omelaniuk 2005; Scarpa 2005).

Child trafficking is also causally linked with migration, as demonstrated in many countries including Bangladesh. With a very low average per capita income, Bangladesh is one of the largest migrant-exporting countries in Asia. Migration takes place to the West, to the Middle East, to Southeast Asia, and to India and Pakistan. The major destinations of trafficked children in Bangladesh include India, Pakistan, the Middle East, and the developed countries. It has been reported that an estimated 40,000 girls are exploited in Pakistani brothels. From January 2000 to June 2003, about 2,405 Bangladeshi children disappeared. Of those, 510 boys and 451 girls were confirmed to have been trafficked. Street children living in the capital are among the 
prime targets of organized child-trafficking rings. According to some surveys, Pakistan and oil-rich Arab states are the principal destinations of Bangladeshi children. Boys are mostly taken to the Persian Gulf (particularly the United Arab Emirates) to work as camel jockeys or farm workers, while the girls often end up working in brothels in India and Pakistan. There have been reports of trafficking in organs in Bangladesh (Dasgupta, 2003). A group of Anthropologists from the United States claims to have encountered 'kidney theft' in Bangladesh (Scheper-Hughes, 2001). Migration provides a constant supply of vulnerable migrants who are easily coerced and deceived into a trafficking situation. Therefore, trafficking is the 'dark side' of movement.

At the same time, it is also important to understand that the two concepts, though interrelated, are distinct. Trafficking is a violation of human rights; migration is a tool for development and a livelihood issue. India shares a 4,222-kilometers border with 28 Bangladeshi districts. Bangladeshi traffickers have built up bases in the border districts of India, in West Bengal and Assam, to the north and west. The porous borders of Bangladesh, which are shared with India and Myanmar, are also conducive to external trafficking. A particularly well known land route used to traffic women and girls to India is the Benapole border crossing, which is well connected with Kolkata, which is renowned for its sex industry. Some of the routes identified by the Government of Bangladesh include:

a) Route 1: from Dhaka to Barisal by launch and from there to Jessore, Satkhira

b) Route 2: from Barisal to Benapole and other border areas via Jessore

c) Route 3: from Gabtoli, Dhaka to Jessore and Satkhira via Aricha

d) Route 4: from Gabtoli, Dhaka to Chapai Nawabgang and other border areas via Nagarbari

e) Route 5: from Gabtoli, Dhaka to Darshana by bus and from there to several border areas.

f) Route 6: from Gabtoli, Dhaka to Dinajpur and Lalmonirhat by bus and from there to different border areas. 
Despite an increase in recent years government and international responses to trafficking, there is insufficient awareness about its causes to identify who is vulnerable and why (Rigby, 2010). There is no guiding theoretical framework attempting to understand the complex inter-relationship of the social, economic and cultural factors that contribute to the trade (Rafferty, 2007; Omelaniuk, 2005). People from any background may be vulnerable to exploitation through trafficking (Wirtz, 2009). The causes of trafficking vary and differ from one country to another such that any antecedents and contributory factors may not apply universally (UNODC, 2006). Factors that have been identified are often categorized into the 'push' and 'pull' factors related to the personal, social and economic circumstances in source and destination countries. Push factors may include poverty, gender inequality; armed conflicts, low educational attainment and family break up; while the pull factors include the demand for cheap sex and labour and the high rewards for traffickers.

Save the Children (2007) found that the natural livelihood and food insecurity due to natural disaster are linked with trafficking in persons in Bangladesh, particularly women and children. Natural disasters and calamities can create vulnerabilities for the children. During the SIDR (a super cyclonic storm in the Bay of Bengal in 2007) in Southkhali, 400-500 Bangladeshi children who have lost their parents are now living with relatives. The financial cost this imposes on already poor families increases these children's risk of child labour, trafficking and other forms of exploitation. The criminal traffickers are taking advantage of the situation and making business on these vulnerabilities. The criminal chain is long, starting from Bangladesh to Europe and America. Globalization has severed the traditional socioeconomic fabric and has made women and children vulnerable. They are increasingly becoming a commodity to be sold in the 'world market'. Environmental degradation, ecological erosion and the destruction of biodiversity-based production systems further accelerate the process. So, one cannot blame the people moving out in search of food and work. Free market forces are responsible for the disintegration of rural communities. In turn, are leading towards even more poverty of the already destitute.

The consequence of child trafficking has two dimensions - internal and external. Internally, Bangladesh suffers from many negative aspects for the 
continuing incidence of child trafficking. Externally, the failure to combat child trafficking by the government also results in serious international pressure on the country. For example, the United States Department of State placed Bangladesh on 'Tier 2' in its 2005 Trafficking, in Persons Report. 'Tier 2' countries are those who's Governments do not fully comply with minimal standards, but are making significant efforts to combat trafficking. The report of the United States Department of State (2012) argues that Bangladesh does not fully comply with the minimum standards for the elimination of trafficking; however, it is making significant efforts to do so. In December 2011, the government enacted a comprehensive anti-trafficking law, which addressed legislative gaps such as the absence of a prohibition on the trafficking of men. The government also approved a new anti-trafficking action plan, which incorporated necessary steps to implement the new law. Although the law does not include a specific prohibition on fraudulent recruitment, it cites the concept of fraud as a possible element of human trafficking. The number of prosecutions increased, but the number of convictions declined as compared to the previous year. Bangladesh has to update its position in various international meetings regarding her commitments to child rights related conventions and protocols.

The Conventions of the Child Rights (CRC) is one of those critical instruments. Bangladesh as the state party to the CRC is responsible for submitting an initial report two years after ratification and periodic report every five years thereafter. Bangladesh submitted the initial report and second periodic report to the Committee in 1995 (due in 1992) and 2000 (due in 1997) respectively. The Committee gave their Concluding Observations on the reports with some specific recommendations for improving the lives of the Bangladeshi children. Bangladesh, however, could not offer the third report, which was due in 2002. Subsequently, the Committee allowed Bangladesh to submit the third and fourth periodic reports as one consolidated report in September 2007. The Committee considered the initial report (CRC/C/3/Add.38) and Supplementary report CRC/C/3/Add.49) of Bangladesh at its 380th to 382nd meetings (CRC/C/SR.380-382), on 26 and 27 May 1997. The 
Committee reviewed the present situation of the CRC and provided some recommendations. The Committee welcomes the establishment of a Ministry of Women and Children's Affairs in 1994. It also notes with appreciation the adoption of the National Policy for Children as well as the establishment of the National Children's Council in August 1995. In the area of legislative reform, it notes the adoption of a plan of action to create task forces on law reform, juvenile justice and the girl child. The adoption in 1995 of the Repression against Women and Children (Special Provision) Act and the active participation of Bangladesh in the SAARC (South Asian Association for Regional Cooperation) Decade of the Girl Child is also welcomed.

The Committee also welcomes the NGO, community and the Government, both at national and local levels, to monitor and implement the rights of the child. The Committee found some principal subjects of concerns. The Committee was unclear about status of the Convention in the domestic legal framework and the insufficient steps taken to bring existing legislation into full conformity with the Convention. These include the general principles of non-discrimination (Article. 2), the best interests of the child (Article 3), the right to life, survival and development (Article 6), and respect for the views of the child (Article 12). Among the concerns are:

1) the lack of conformity between existing legislative provisions and the Convention with respect to the various age limits set by law,

2) the lack of a definition of the child, and the age of criminal responsibility, which is set at too young an age,

3) the possibility of imposing the death penalty, and/or imprisonment of children 16-18 in ordinary prisons,

4) Regarding the implementation of Article 12 of the Convention, noting that the views of the child are not sufficiently taken into account, especially within the family, the school and the juvenile justice system.

The committee provided a number of suggestions. One of it is to review the Vienna Declaration and Programme of Action, in particular its reservations to Articles 14, Paragraph 1, and 21 of the Convention with a view to their withdrawal. The State party pursue its efforts to ensure full compatibility of its national 
legislation with the Convention, taking due account of the general principles as contained in Articles 2, 3, 6 and 12 and the concerns expressed by the Committee. Furthermore, the State party should develop a national policy on children and integrated legal approach to child rights.

\section{COMBATING CHILD TRAFFICKING}

\section{Responses of Government organizations (GOs)}

Trafficking is the worst form of violation of human rights. Anyone involved in the process is guilty of a crime that results in the unacceptable exploitation of people. Different state and non-state actors are engaged in combating child trafficking in Bangladesh. In this context, three types of responses are widely visible government, non-government and international organizations and multilateral initiatives. The Bangladesh response to child trafficking has often been praised by the international organizations such as ILO (2006). The commitments in place are consistent with a number of provisions of the Bangladesh Constitution, such as:

1) the fundamental rights of equality and equal protection (Article 27),

2) right to be free from discrimination on the basis of religion, race, caste, sex or place of birth (Article 28),

3) Right to protection of the law (Article 31),

4) Prohibition against forced labour (Article 34),

5) torture and cruel, inhuman or degrading treatment (Article 35); and

6) Freedom of movement (Article 36).

The National Children Policy, formulated in 1994, has been a milestone in the history of protection of the rights and life of children in Bangladesh. This policy has subsequently emerged as a major focus of GOB's activities for children and their future. Bangladesh is a signatory to the Convention on the Rights of the Child (CRC). Bangladesh is one of the first few countries to ratify the Convention. The Government has increasingly placed a high priority on both preventing and 
confronting violations of children's rights such as abuse and exploitation, loss of liberty, child marriage, and birth registration. These commitments are manifested in the preparation and adoption of the National Plan of Action against Sexual Abuse and Exploitation of Children including Trafficking in 2002. An Implementation and Monitoring Committee has been established to ensure coordination and monitoring of the National Plan of Action (NPA). The major goal of this National Action Plan is to protect children from abuse, violence, discrimination and sexual exploitation, including trafficking.

Bangladesh has ratified the two Optional Protocols to the CRC in 2000. The first protocol is on the Sale of Children, Child Prostitution and Child Pornography. The second protocol include the Involvement of Children in Armed Conflict, ILO Convention 182 on Elimination of Worst Forms of Child Labour in 2001, 1949 Convention on the Suppression of Traffic of Persons, and the 1956 Slavery Convention. In 2002, Bangladesh ratified the SAARC Convention on Preventing and Combating Trafficking in Women and Children for Prostitution. The Government has committed itself to consensus building on children's rights through the Global Movement on Children. The participation of the Prime Minister of Bangladesh at the United Nations General Assembly Special Session (UNGASS) in 2002 is a demonstration of this political will of the Government. Bangladesh is also a signatory to the Asian and Pacific Decade of Disabled Persons (1993-2002).

The Government has enacted several child protection focused laws. These include the Suppression of Violence against Women and Children (Amendment) Act of 2003, The Disability Welfare Act of 2001, The Acid Control Act of 2002, The Acid Crimes Control Act of 2002, The Law and Order Disruption Crimes (Speedy Trial) Act of 2002, and the Birth and Death Registration Act of 2004. Prostitution and trafficking for the purpose of prostitution or other immoral acts are covered in the Penal Code and Suppression of Immoral Traffic Act. The 2003 Suppression of Violence against Women and Children Act punishes the crime of trafficking in children and women by capital punishment or imprisonment for life and a fine. The 1993 Suppression of Immoral Traffic Act prohibits keeping a brothel or allowing the usage of premises as brothels, soliciting for the purposes of prostitution, living on the money transacted in prostitution, procuring individuals for the purpose of 
prostitution, importing a female for the purpose of prostitution, and detaining a woman for the purpose of prostitution. The act also prohibits encouraging a girl under 18 to be in prostitution. The Penal Code prohibits procurement of a girl under the age of 18 for illicit intercourse with another person; selling, letting, hiring, or disposing of minors under the age of 18 for the purpose of prostitution; and buying minors for the same purpose.

In addition, the code prohibits abduction. The constitution of Bangladesh prohibits forced labour. The prohibition of forced labour does not apply to compulsory labour, which is labour performed by people undergoing lawful punishment for a criminal offense or labour required by any law for a public purpose. The Factories Act of 1965, as well as the Shops and Establishment Act of 1965, also prohibits forced labour and establishes an inspection system to enforce this prohibition. The Factories Act bars children under the age of 14 from working in factories. The Employment of Children Act prohibits children under the age of 15 from working in any occupation 'connected with transport of passengers, goods, or mails by railway' or involving the 'handling of goods within the limits of any port'. Thus, it shows that there is an ample scope to protect children from trafficking or any other crime.

The Ministry of Women and Children Affairs (MWCA) carried out a 3-year pilot project called Coordinated Program to Combat Child Trafficking. As a result, a counter trafficking framework report was published to help the Bangladeshi government with its future counter trafficking plan of action. MWCA operates support centres at six divisional levels that offer shelter and training for rehabilitation. The ministry also hosts a rehabilitation centre for destitute children and a home for boys. The National Task Force for Anti-Child Trafficking was formed under this project. As part of its anti-trafficking measures, the Government created a fast-track court to prosecute trafficking offences. Yet, no convictions have been made to date. 


\section{Responses of Non-government and International organizations (NGOs and INGOs)}

The NGOs and INGOs operating in Bangladesh are considerably committed to protecting children from trafficking in order to establish justice for the children in Bangladesh. They are working to prevent human trafficking, provide resources to victims and arrest and prosecute child-sex offenders. Bangladesh Shishu Adhikar Forum (BSAF), Manusher Jonno Foundation, the Bangladesh chapter of Action against Trafficking and Sexual Exploitation of Children (ATSEC) and Bangladesh Forum against Human Trafficking are some of the NGOs are deeply engaged with child trafficking issues. Child Labour Watch Forum, Bangladesh, demanded formulating a national child protection policy to accommodate the provision of prohibiting all non-institutional child labour including the catching of fishes by children of remote Dublar Char in the Bay of Bengal in the deep sea. NGOs (i.e., Association for Community Development (ACD), Action against Trafficking and Sexual Exploitation of Children (ATSEC), Bangladesh national Women Lawyers Association (BNWLA), Aid Comilla, Bangladesh Institute of Theatre Arts (BITA), Centre for Rights and Development (CRD), Centre for Women and Children Studies (CWCS), Dhaka Ahsania Mission (DAM), Rights Jessore, Palli Gana Sanhati Parishad (PGSP), SHETU Bangladesh and Samaj Paribartan Kendra (SPK) have incorporated child and women trafficking issues together with their awareness raising activities. BNWLA, ACD, DAM are mainly involved in establishing shelter home facilities and directly working in the areas of rescue, repatriation, recovery and integration. There are no bilateral treaties regarding the repatriation of those survivors seeking to return to Bangladesh. BNWLA, ACD, DAM are mainly involved in establishing shelter home facilities and directly working in the areas of rescue, repatriation, recovery and integration.

The existing networks of NGOs and international alliances could work as catalysts and advocates for promoting an enabling environment to convince the government and concerned agencies to start negotiating bilateral agreement and treaties. ACD, BNWLA and DAM are also involved in helping trafficking survivors by seeking out legal guardians and organizing family reunions. The main approach to integrating trafficked victim children and women is to engage them in non-formal or 
formal education systems, and organize special vocational training for developing skills.

Major bilateral and multilateral donors supporting the programs related to the protection of child trafficking in Bangladesh include Save the Children UK, Plan Bangladesh, Asia Development Bank AUSAID European Commission, International Organization for Migration (IOM), ILO-IPEC, NORAD, UNDP, UNICEF, USAID, and World Bank. The Ministry of Labour and Employment has also implemented a USAID funded project aimed at the Eradication of Hazardous Labour in Bangladesh. In collaboration with the World Food Program (WFP), the Government started the Food for Education Program in 1993 with the aim to attract poor children and their families to primary education.

Child trafficking is increasingly treated as a priority issue in the process and structure of multilateral cooperation. In this context, the role of ILO in Bangladesh is significant. ILO Convention No. 182 (1999) on the Worst Forms of Child Labour (WFCL) classifies trafficking among 'forms of slavery' or 'practices similar to slavery' and thereby a WFCL is to be eliminated as a matter of urgency, irrespective of the country's level of development. There are efforts by the ILO to integrate child labour and trafficking concerns into Education for All. The ILO's International programme on the Elimination of Child Labour is working with government, workers and employers' organizations and NGOs to fight child. Through the endorsement in 2006 of the ILO's Global Action Plan against the worst forms of child labour, all 183 member States have committed themselves to eliminating all WFCL including trafficking in children by 2016 (ILO, 2005).

There is global resistance against trafficking and the real causes of trafficking are being traced so that it can stop. Article 36 of the $\mathrm{CRC}$ requires States to 'protect the child against all other forms of exploitation prejudicial to any aspects of the child's welfare'. Article 34 obliges State parties to protect children from all forms of sexual exploitation and sexual abuse and take national and bilateral measures to 
prevent: a) the inducement or coercion of a child to engage in any unlawful sexual activity; b) the exploitative use of children in prostitution or other unlawful sexual practices; and c) the exploitative use of children in pornographic performances and materials.

The South Asian Association for Regional Cooperation (SAARC) Convention on Preventing and Combating Trafficking in Women and Children for Prostitution 2002 is another milestone in multilateral initiative contributing to fight against the menace of trafficking in child. The SAARC Convention 2002 deals with Trafficking in Women and Children for the purpose of Prostitution. The Convention follows the early approach to trafficking, which linked the trafficking only to prostitution and sexual exploitation. The SAARC Convention on Regional Arrangements for the Promotion of Child Welfare in South Asia 2002 has also added further rigour in this connection. The Convention follows the CRC and defines a child as a person below 18 years of age, unless under national law majority is attained earlier.

\section{RECOMMENDATIONS AND CONCLUSIONS}

The paper discussed the features and causes of child trafficking and the responses of the governmental and non-governmental organizations in Bangladesh. It showed that causes of child trafficking in Bangladesh are compound with many aspects. The causes are related with factors, such as poverty and low socio-economic conditions of the country. The problem also is gripped with an international route where globalization and migration are two main rudiments. The discussion about the responses of the governmental and non-governmental organizations gives some distressing notions. There are a lot of gaps between the provisions and commitments, though it was found that a number of initiatives such as CRC, child policy, compulsory primary education, and laws are working in the country. One of the important limitations was the lack coordination within the Governmental and nongovernmental initiatives and vice versa.

To consider the overall situation of the child trafficking in Bangladesh, we propose some specific suggestions, which can help to protect this problem. They are: 


\section{Curative measures}

It is an imperative aspect to take immediate actions for curative measures so that the child tracking can be stopped. This includes providing all sorts of curative services to the police and border guards on the different routes as mentioned in the previous paragraphs. Most important task is to increase the forces to those points including airport so that the children cannot be trafficked. It is necessary to give serious emphasis on combating the incidence of violence, sexual abuse and exploitation of children. Sexual abuse of children and adolescent girls is a problem, which remains hidden due to the stigma attached to the victims or such violence.

\section{Preventive measures}

It is needed for an attitudinal change amongst the people to wipe out the menace from the society. The most important thing is to aware the mass people about the causes and sufferings of child trafficking. An anti-trafficking alert system at bus stations is effective for such awareness. The anti-trafficking network may include representatives of truckers' unions, security forces and social action, and religious groups who identify and report suspected trafficking situations.

\section{Institutional level activities}

The role of the Ministry of Women and Children Affairs, National Children's Council, Inter-Ministerial CRC Committee and Bangladesh Shishu (Child) Academy need to be strengthened to promote the rights of the child in Bangladesh. It is essential to develop a website to track the missing children. Anyone who has lost their child can post a message on this website and the search will be set in motion simultaneously in all cities, in the country.

\section{Policy level activities}

The issue of child labour needs to be focused seriously in the policy and actions at government and non-government levels. Implementation of the Third National Plan 
of Action (NPA) for Children (2005-2010) need to be considered; as well as the A World Fit for Children' adopted by General Assembly at its Special Session on Children and the MDGs. A Counter Trafficking Programme Strategy (CTPS) that focuses on how programming can be planned, implemented and monitored, who / which agency is responsible for different aspects can be developed. The counter also, can provide a timeframe against which concrete progress can be developed. There is a need for a single definition about the age limit of child in Bangladesh. In some cases, it is mentioned that child age limit is 18 (National Plan of Action for Children 2005, p. 17) while in the national policy document it is decided at the age of 14 . Such discrepancies, in laws and policies, need to be addressed.

\section{Partnership and networking}

Partnership and networking can be considered as most significant task for protecting child trafficking. We found that the causes of child trafficking are manifold and interrelated with each other. We need to work in a partnership basis such as a partnership between Bangladesh and neighbouring countries, GOs and NGOs, GONGO and civil society, etc. A strong network can provide many opportunities to strengthen this partnership. It takes into account the national, sub-regional and regional specificities of the children's vulnerability, mechanisms, and routes used by traffickers, and the nature of exploitation that takes place, as well as the legal and cultural contexts.

\section{Proper coordination}

It was seen that there are a number of child welfare initiatives in Bangladesh, which are related to protect child trafficking, but these are not functioning well due to the lack of coordination. Coordination between the GOs and NGOs is crucial. However, we also need to coordinate all initiatives to achieve a long-term goal to protect child trafficking.

\section{REFERENCES}

Africa Research Bulletin. (2004). Social and cultural: Child trafficking-scale of African slavery revealed. Blackwell Publishers Ltd: Global News Wire-Asia African Intelligence Wire. 
Alamgir, M. (2004). Combating trafficking in women and children in Bangladesh. Dhaka: Ministry of Home Affairs, Government of Bangladesh.

Altink, S. (1995). Stolen lives: Trading women into sex and slavery. London: Scarlet Press.

Bastia, T. (2005). Child trafficking or teenage migration? Bolivian migrants in Argentina. International Migration, 43(4), 58-89.

Blanchet, T. (2002). Beyond boundaries: A critical look at women labour migration and the trafficking within. Prepared for USAID, Drishti Research Centre, Dhaka.

Bertone, A. M. (2000). Sexual trafficking in women: International political economy and the politics of sex. Gender Issues, 18(1), 4-22.

Bump, M. N., \& Duncan, J. (2003). Conference on identifying and serving child victims of trafficking. International Migration, 41(5), 201-208.

Coomaraswamy, R., \& Satkunanathan, A. (2006). Anti-child trafficking legislation in Asia: A six-country review. Bangladesh, Nepal, Pakistan, Sri Lanka, Thailand \& Indonesia. Geneva: ILO.

Dasgupta, A. (2003). Dreams and hunger-drive trafficking into India. India: Inter Press Service.

Dottridge, M. (2004). Kids as commodities: Child trafficking and what to do. Lausanne: Terre des Homes.

Firoze, F. K. (2006). Trafficking in globalized situation: A South Asian perspective. Lausanne: Terre des Homes.

Foundation of Women's Forum. (1998). Trafficking in women for the purpose of sexual exploitation: Mapping the situation and existing organisations working in Belarus, Russia. The Baltic and Nordic States. Foundation of Women's Forum, financed by the Swedish Ministry for Foreign Affairs, Stockholm.

Gjermeni, E., Van Hook, M. P., Gjipali, S., Xhillari, L., Lungu, F., \& Hazizi, A. (2008). Trafficking of children in Albania: Patterns of recruitment and reintegration. Child Abuse and Neglect, 32, 941-948.

Government of Bangladesh. (2007). Bangladesh country report on combating trafficking of women and children. Dhaka: Government of Bangladesh.

Heissler K. A. (2013). Rethinking 'trafficking' in children's migratory processes: The role of social networks in child labour migration in Bangladesh. Children's Geographies, 11(1), 89-10. 
Human Rights Watch (2003). Togo: Borderline slavery: Child Trafficking in Togo, Vol. 15, Number (8(A), Togo: Human Rights Watch.

International Labour Organization (ILO). (2005). Trafficking in children. Geneva: ILO.

Geneva: ILO.

(2006). Anti-trafficking review.

International Organization for Migration (IOM). (1995). Trafficking and prostitution: The growing exploitation of migrant women from central and eastern Europe. Migration Information Programme, Geneva: IOM.

human trafficking: A global survey. Geneva: IOM.

(2005). Data and research on

International Labour Organisation/International Programme on the Elimination of Child Labour (ILO/IPEC). (2001). Synthesis report on trafficking in children for labour in West Africa and Central Africa. Geneva: ILO.

Joffres, C., Mills, E., Joffres, M., Khanna, T., Walia, H., \& Grund, D. (2008). Sexual slavery without borders: Trafficking for commercial sexual exploitation in India. International Journal for Equity in Health, 7(22), 1-11.

Laczko, F., \& Gramegna, M. (2003). Developing better indicators of human trafficking. Brown Journal of World Affairs, 10 (1), 179-194.

Lazaridis, G. (2001). Trafficking and prostitution: The growing exploitation of migrant women in Greece. The European Journal of Women's Studies, 8(1), 67-102.

Lederer, L. (2001). Human rights report on trafficking on women and children: Protection report. Baltimore, MD: Johns Hopkins University.

Lincoln, Y. S., \& Guba, E. G. (1985). Naturalistic inquiry. Beverly Hills, CA: Sage Publications, Inc.

Mattar, M. (2003). Slavery and human trafficking. Testimony presented to the House Government Reform, Subcommittee on Human Rights and Wellness, US Congress.

Miles, M. B., \& Huberman, A. M. (1994). An expanded sourcebook: Qualitative data analysis. Thousand Oaks, CA,: Sage.

Ministry for Foreign Affairs (Sweden). (2001). Trafficking in women and children in Asia and Europe: A background presentation of the problems involved and the initiatives taken. Stockholm: Ministry for Foreign Affairs.

National Plan of Action for Children (2005). National plan of action for children, 2005-2010, Bangladesh. Dhaka: Bangladesh. Ministry of Women and Children Affairs. 
Omelaniuk, I. (2005). Trafficking in human beings. UN expert group meeting on international migration and development, New York: United Nations.

Rafferty, Y. (2007). Children for sale: Child trafficking in Southeast Asia. Child Abuse Review. 16, 401-422.

Raymond, J., \& Hughes, D. (2001). Sex trafficking of women in the United States: International and domestic trends (monograph). Washington, DC: Coalition Against Trafficking in Women.

Renton, D. (2001). Child trafficking in Albania. Tirana: Albania: Save the Children.

Richard, A. O. (1999). International trafficking in women to the United States: A contemporary manifestation of slavery and reorganized crime. USA: The Center for the Study of Intelligence.

Rigby, P. (2010). Human trafficking-A role for youth and criminal justice workers. Scotland: Criminal Justice Social Work Development Centre.

Ryan, C., \& Hall, C. (2001). Sex tourism: Marginal people and liminalities. London: Routledge.

Sanghera, J. (1999). Trafficking of women and children in South Asia: Taking stock and moving ahead. A broad assessment of anti-trafficking initiatives in Nepal, Bangladesh, and India. Kathmandu: UNICEF ROSA and Save the Children Alliance.

Save the Children Canada. (2003). Children still in the chocolate trade: The buying, selling and toiling of West African child workers in the multibillion dollar industry. Toronto: Save the Children Canada.

Save the Children (2007). State of child rights in Bangladesh 2007. Save the Children Alliance SITREP No. 7-22 November 2007, Bangladesh Cyclone Sidr.

Scarpa, S. (2005). Child trafficking: The worst face of the world. Global Migration Perspectives No 40, Geneva: Global Commission of International Migration.

Scheper-Hughes, N. (2001). The organ of last resort. UNESCO Courier, 54(7\&8), 50 .

United Nations Children's Fund (UNICEF). (2002). Child trafficking in West Africa: Policy responses. Florence, Italy: UNICEF.

violence, exploitation and abuse. Dhaka: UNICEF.

(2003). Child protection from 
Retrieved from http://web/unicef.org.

(2005). Fact sheet: Trafficking.

(2006). Fact sheet:

Trafficking. Retrieved from http://www.unicef.org/protection.filies.trafficking.pdf.

United Nations. (2000). The United Nations Convention against Transnational Organized Crime. General Assembly resolution 55/25, New York: United Nations.

(2004). Training manual. For combating trafficking of women and children. Retrieved from www./un.org.traffickingproject.

US Department of State. (2005a). Trafficking in persons report. The office to monitor and combat trafficking in persons. Retrieved from http://www.state.gov/g/tip/rls/tiprpt/2005/46606.htm.

.(2005b). UN "International Protocol to Prevent, Suppress, and Punish Trafficking in Persons, especially Women and Children. New York: US Department of State.

. (2012). Trafficking in persons report - Bangladesh.

Geneva: UNCHR.

United Nations Office on Drug and Crime (UNODC). (2006). Toolkit to combat trafficking in persons. New York: United Nations.

Vienna: UNODC.

. (2012). Global reports on trafficking in persons.

Wirtz, L (2009). Hidden children: Separated children at risk children's society. London: The Children's Society. 